\title{
An Course Reform on Modern Communication Technology for Communication Engineering Specialty in Application-Oriented Universities
}

\author{
Min Wang, Qiaoyun Sun, Shuguang Zhang, and Yu Zhang
}

\begin{abstract}
To improve the teaching quality of the course "modern communication technology" for the application-oriented undergraduate in communication engineering specialty, it considers the location and characteristics of this course to analyze the existing problems in the present teaching. The causes of the systematic teaching contents, the traditional teaching method and the single assessment mode are discussed. It mainly reforms from the three aspects of teaching content, teaching method and curriculum evaluation. And the solution measures of the teaching content distribution according to the integration update need, the methods and means harmonization of the diversification, the process evaluation of the consistent target are proposed.
\end{abstract}

Index Terms-Modern communication technology, course reform, communication engineering, teaching quality.

\section{INTRODUCTION}

Communication engineering is a practical and professional major. With the rapid development of communication technology, the society has higher requirements for the training of communication engineering specialty, which brings new challenges to the teaching of this specialty. The cultivation of application oriented communication talents can not be confined to the theoretical knowledge, but also to train students' ability to apply the theory into practice. The construction of communication engineering specialty should highlight the application that is the key to the whole process of teaching. The course of modern communication technology focuses on the combination of the communication theory teaching and the communication practice, and it emphasizes on both the principle of communication system and the communication technology application, so as to establish the scientific and reasonable course orientation and target ability to the talent training of communication engineering. This course is a core course of communication engineering specialty, which is of great significance to the training of applied talents of undergraduate colleges.

Modern communication technology is a very important course in the communication engineering specialty. It is not only the transition from the basic course to the specialized

Manuscript received January 8, 2016; revised March 29, 2016. This work was supported by the non-governmental education promotion project of Beijing: comprehensive practical teaching base for modern communication technology in Beijing City University and the comprehensive reform project of communication engineering specialty in Beijing City University (zy2014102).

Min Wang, Qiaoyun Sun, Shuguang Zhang, and Yu Zhang are all with Beijing City University, School of Information and Communication Engineering, 100083 Beijing, China (e-mail: wangmin@bcu.edu.cn). course, but also the introduction course of the communication subject. The teaching effect of this course has a direct influence on the teaching quality of the knowledge structure and the comprehensive ability of the trained personnel. However, there are problems such as the systematic teaching content, the traditional teaching means and the single examination method [1]. In addition, according to the position and characteristics of modern communication technology, how to update frontier technology and knowledge, mobilize the enthusiasm of the students, and really evaluate the students professional ability is the most important. In order to improve the teaching quality of the modern communication technology course, the course reforms on teaching contents, training methods and examination means are very urgent [2]. This paper analyses the existing problems of the slow update teaching contents, the traditional teaching means and the single examination methods in the course of modern communication technology, and discusses the specific implementation of the curriculum reform.

\section{ORIENTATION AND CHARACTERISTICS OF MODERN COMMUNICATION TECHNOLOGY}

\section{A. Course Orientation}

Modern communication technology is a professional course in communication engineering specialty. By learning this course, students can master the basic theory and experimental skills of communication lines and system, understand the information transmission technology, master the information and communication system installation, commissioning and maintenance methods. The purpose of this course is to train the students to master the basic operations, configuration and maintenance of ZTE ZXJ10 SPC and ZXMP SDH optical transmission equipment, which can improve the operation ability of communication equipment and deepen the understanding of theoretical knowledge for the future of employment to lay a good foundation.

At present, the study of communication technology is focused on a specific technology, such as program control exchange, mobile communication, optical fiber communication, so students are very difficult to establish the overall concept of communication. From the perspective of the whole network about the various types of communication technology, the involved communications technology in this course is to learn the details of the discussion. It builds a scientific, accurate, systematic, integrity, novel and practical knowledge structure and content system, which is to lay a 
necessary theoretical and practical basis for all kinds of modern communication system management, maintenance, and application development.

\section{B. Course Characteristics}

\section{1) Comprehensive and modular teaching content}

This course adopts the idea of the basic concept, the basic principle, and the basic professional skills to establish the concept and system of modern communication technology. From the time and space aspects of the comprehensive and history, it gives the students the gradual display of the professional and technical communication at all levels and the characteristics of products in the different development periods. This course can finds out the basic rule of technology development from the history of communication technology and comprehensively display the inherent laws by all levels of communication technology.

The arrangement of teaching contents with modular structure, mainly including telephone communication technology, mobile communication technology, optical fiber communication technology, microwave communication, satellite communication technology and data communication technology. Each module is composed of the relevant knowledge about the concept and theory of the actual communication system and its application. It includes both the commonness of the basic components of the communication system and the unique personality of the key technology and application of each communication system, which is to stimulate the interest of students' learning and research.

\section{2) Comprehensive and modular teaching content}

In view of the different knowledge points to take teaching methods, the demonstration method, case method, heuristic method, practice method, experimental method and other teaching methods are adopted to fully mobilize the enthusiasm of students. The practice teaching improves the skills of students in the progressive layers of the practice teaching system by the practical experiment and training, the communication equipment test maintenance, and the communication platform operation. It can develop the practical ability to analyze and solve the problems, and lay a solid foundation for students in the future job practices.

Modern communication technology comprehensive training room makes students familiar with operating platform configuration. It can use the existing network equipment to operate engineering experimental settings. Thus, students can better adapt into the late social practice by training and improving the operation skills.

\section{3) Traditional and examinational course assessment}

In the course assessment, it generally strengthens the process of the assessment, such as the homework out of the classroom and the experimental test. The total grade includes the four parts of the usual attendance (15\%), class performance $(15 \%)$ and experimental test $(20 \%)$, and final exam $(50 \%)$.

Final exam can adopt open or closed book for examination questions. It involves basic concept, basic theory, and integrated application. And its questions can adopt all kinds of styles, such as determine questions, fill in the blanks, choice questions, short answer questions and applied questions.

\section{PRESENT SituAtion AND REASON ANALYSIS OF MODERN COMMUNICATION TECHNOLOGY}

\section{A. Systematic Teaching Content and Slow Real-Time Update of the Advanced Technology}

As the knowledge introduction course, modern communication technology has the characteristics of the knowledge updating fast and the strong industry practice. At present, the teaching content of modern communication technology is the introduction of a lot of mainstream communication system. Compared with other professional courses, the content of modern communication technology is wide and the concept of it is strong. At the same time, the communication technology and communication system in the modern society develops very fast, and the teaching content is relatively slow update [3]. Therefore, it is difficult for the students to better combine the classroom knowledge and the practical communication technology by the only teaching content of the books. In teaching practice, the teachers must guide the students to actively learn new professional knowledge and new skills, and they should aim to introduce the new frontier technology and knowledge in the classroom teaching. Additionally, it is important for mobilizing the students' conscious learning activity and paying attention to the dynamic forefront technology to achieve better learning effective.

\section{B. Traditional Teaching Method and Poor Learning Enthusiasm of the Students}

The center of the traditional teaching method is based on the knowledge system, which teaches the theory firstly and then trains some practical experiments. Thus, it only uses a lot of boring theory to guide students. The students are not easy to understand and lack of learning interests. The theory knowledge is the teaching core in the teaching process, but students' mathematical basis is generally weak and their theoretical reasoning ability is poor. They are often lack of learning enthusiasm and can not focus on teaching in the class. In addition, the practical application of knowledge is only for ornament and the students only do the part of experiment class, who have the little experience in the field operation. Therefore, it is hard to solely rely on the imparting knowledge by classroom teacher to inspire students' interest and enthusiasm. And it is also difficult to series a large number of scattered knowledge, the students can not make comprehensive use of knowledge after listening to the teacher [4].

\section{Single Course Assessment and Hard Evaluation of the Students' professional Ability}

The curriculum assessment of the final grade is generally determined on the final exam, and it often uses the open or closed book written form through objective evaluation on the basic concepts, basic theory, comprehensive application of knowledge to fill in the blanks, choice questions, short answer questions and applied questions. And the course assessments generally strengthen the process assessment, such as the 
assessment of classroom work and the experimental process with a certain percentage of the total score. The way of this assessment in a certain extent can reflect the actual learning situation of students, but it is difficult to assess the students' professional ability. Some students do well in analyzing and solving the problems in the experiment and practical application, but their ability to summarize and review the exam is poor. However, some students can achieve high score in the exam paper and do nothing while meeting the practical problems. It can be seen that the real evaluation of the professional ability needs more information from the actual learning process of the students.

\section{COURSE REFORM OF MODERN COMMUNICATION TECHNOLOGY}

\section{A. Teaching Content Distribution according to the Integration Update Need}

\section{1) Dynamic integration of knowledge module}

The reconstruction and optimization of teaching content depend on the important knowledge of the course, and it changes the traditional way of the different part of communication system. The arrangement of course content creates the serial structure from the basis of the parallel knowledge structure module. The communication professional knowledge is very extensive as the communications major entry course. The main line of this course is communication system and technology application, namely telephone communication technology, optical fiber communication technology, microwave communication technology, satellite communication technology, and the most popular mobile communication technology and data communication technology. According to the development of communication technology, the teaching content is to be integrated and the contents of the traditional communication are reduced. The knowledge module is decomposed into a number of capacity points, which is transformed into the curriculum content that is composed of professional knowledge and skills training.

\section{2) Real-time updating of knowledge content}

The knowledge content of modern communication technology is considered as the core, and it strives to update the knowledge imparting. It is well known that the rapid development of modern communication technology is a feature of the rapid development of modern communication industry and business. Under the ensuring the stability of the original communication system and technology, the new technology is followed and the course contents can be deleted and the content of the new technology is added [5]. In the actual teaching with the latest communications technology as the key supplement, it focuses on the practical application of the combined with the introduction of learning without rigidly adhering to the textbook contents. The new knowledge of things networks, triple play, big data, the development prospect and the existing problems are introduced to arouse students' interests. On this basis, it is further involved in the telecom network knowledge, sensor network technology and RFID technology. However, These new theory and technology can not be updated in a timely manner of the conventional materials, which requires teachers to keep up with the technical development in the dynamic forefront.

\section{B. Teaching Methods and Means Harmonization of the Diversification}

\section{1) Teaching by different classes-the diversified teaching} methods based on curriculum characteristics

The type of professional communication course is rich, it changes the traditional design teaching and the integration of knowledge, methods and technique is adopted. According to the characteristics of this course, the best suitable teaching method is to mobilize the students to actively participate in teaching. Modern communication technology, which involves a wide range of knowledge modules of communication system technology, can be used to discuss and project teaching method [6]. In this course, the teaching mode of the only training has been unable to obtain satisfactory teaching effect, and it is urgent to reform the teaching mode. Research teaching is a teaching method which is based on the students' cognitive rules and guides the students to master the knowledge. This teaching broke the traditional teaching methods, and includes individual self-study, group discussions and subject presentation. The research teaching can stimulate students' interest, highlight the students' main body position, change closed type teaching into open teaching, which is full of vigor for teaching method.

2) Training by different students-the multi-level teaching methods based on students' personalities

The students' learning foundation is different, and the difference of learning enthusiasm is different too. For each student's characteristics, the teaching method adopts the combining of passivity and initiative. The use of existing teaching methods focus on the blackboard and multimedia classroom teaching, so that students can obtain professional knowledge from the passive teaching of "want to learn". Furthermore, it makes full use of network teaching platform to enable students to consolidate knowledge contents by the active teaching "I want to learn" . It broadens the professional vision, improves the ability of autonomous learning, and provides professional space of self study students. The specialized teaching website method, which is the formation of "network, electronic version, interactive teaching and counselling, greatly help the teachers update the teaching contents. Thus, the formation of" student learning "teaching mode is proposed to create a better learning environment for the related communication professional knowledge.

\section{Course Process Evaluation of the Consistent Target}

\section{1) Examination by different learnings-the process consistent target based on assessment contents}

The examination using a variety of forms of written examination is an important test means rather than the only means, the students' evaluation is refined and quantified to the teaching process. It specially sets up experiments and training skills assessment in the actual operation of the students in the process evaluation. It can strengthen the training of the normal exercises and improve the proportion of the total score of the usual results. Another example to carry out test, 
teaching and learning communication, classroom discussion, course group is usually the small interview test, interview and classroom discussion combining interview quiz or test, so that the total usually results can reach about $50 \%$, which can relieve the pressure of a student's final exam. The combination of team and individual stage of the process assessment can be more true reflection of the students in the normal course of the study on the actual learning of the content and results. The investigation report, open book test, test reports, special reports and other forms of process assessment may generally be the course teaching according to the time points for $2 \sim 3$ phase. For each stage of the assessment of the content of knowledge points, the ability to design and implementation of knowledge points is objective for the real test to find out the actual learning level of students.

\section{2) Testing by different talents-the multi-directional assessment methods based on professional Ability}

The assessment of professional competence diversity can be used not only limited to the final written examination, but also equivalent to many sided checking in the professional capacity. The students can choose their own assessment of evaluating achievements. Students can use the general standard of examination papers as curriculum knowledge learning ability; the student individual or group as a unit can be the report mode of curriculum evaluation, the contents of curriculum are summarized in-depth analysis and research, it puts forward their own ideas by the combination of courses and social practice; the individual students with industry identification and certification can be equivalent for the course assessment, and the professional and technical ability are approved; the students participate in academic competitions and college students' innovation and entrepreneurial achievements is the assessment of the professional courses to enhance the students' research ability, innovation ability and the team cooperation ability. Regardless of the manner in which the assessment method of equivalent replacement, it is important in strict accordance with the professional ability of modern communication technology to meet the ability target of the course construction.

\section{CONCLUSION}

Modern communication technology is a core course in communication engineering specialty, the paper analyzes the problem reasons of the slow update teaching contents, the traditional out-date methods, and the single assessment methods by considering the location and characteristics of the course. From teaching contents, teaching methods and assessment means, it proposes the measures and countermeasures to improve the teaching quality of the course, such as the distribution according to integration update need, the methods and means harmonization of the diversification, the process evaluation of the consistent target, which can satisfy the personnel training goals for communication engineering specialty in application-oriented universities.

\section{ACKNOWLEDGMENT}

This paper is sponsored by the non-governmental education promotion project of Beijing: comprehensive practical teaching base for modern communication technology in Beijing City University and the comprehensive reform project of communication engineering specialty in Beijing City University (zy2014102).

\section{REFERENCES}

[1] Z. B. Xie, Y. B. Tian, and P. Y. Yan, "Innovation and practice in modern communication technology," Modern Electronics Technique, vol. 34 , no. 23 , pp. $185-187,2011$.

[2] T. Lu, "The reform of the teaching contents and methods of modern telecom technology in university," Journal of Lishui University, vol. 34, no. 2, pp. 95-97, 2012.

[3] R. Guo, "Modern communications technology course teaching content and training mode reform," Computer Knowledge and Technology, vol. 9, no. 35, pp. 8002-8003, 2013.

[4] R. F. Zhang, L. Fang, and C. Y. Deng et al., "Research on the innovation teaching in modern communication principle," Course Education Research, vol. 19, pp. 254-255, 2013.

[5] L. P. Zhang, "Teaching reform and practice in modern communication technology," China Information Technology Education, vol. 22, pp. 37-38, 2014

[6] H. Y. Liang and H. B. Chen, "On exploration and practice of inquiry teaching in modern communication technology curriculum," Popular Science \& Technology, vol. 15, no. 10, pp. 135-137, 2013.

Min Wang received the Ph.D. degrees from School of Information Engineering in Beijing University of Posts and Telecommunications (BUPT), China, in 2012. She is currently the associate professor in the School of Information and Communication Engineering in Beijing City University. Her research interests include multicast and broadcast, radio resource management in wireless networks.

Qiaoyun Sun received the Ph.D. degrees from School of Information Engineering in BUPT, China, in 2009. She is currently the associate professor in the School of Information and Communication Engineering in Beijing City University. Her research interests include radio resource management in wireless networks.

Shuguang Zhang received the M.S. degree from Beijing University of Posts and Telecommunications (BUPT), China, in 2004. He is currently the associate professor in the School of Information and Communication Engineering in Beijing City University. His current interests are computer communications technology.

Yu Zhang received the Ph.D. degrees from Beijing Jiaotong University, China, in 2013. She is currently the associate professor in the School of Information and Communication Engineering in Beijing City University. Her research interests include wireless communication, personal communication and communication networks. 